OPEN ACCESS

Edited by: Hassane Zouhal,

University of Rennes 2 - Upper Brittany, France

Reviewed by: Johnny Padulo,

University of Milan, Italy Beat Knechtle,

University Hospital Zurich, Switzerland

*Correspondence:

Fábio J. Lanferdin

fabiolanferdini@gmail.com

Specialty section:

This article was submitted to

Exercise Physiology,

a section of the journal

Frontiers in Physiology

Received: 27 June 2020

Accepted: 20 July 2020

Published: 05 August 2020

Citation:

Lanferdini FJ, Silva ES,

Machado E, Fischer G and

Peyré-Tartaruga LA (2020) Physiological Predictors of Maximal Incremental Running Performance.

Front. Physiol. 11:979.

doi: 10.3389/fphys.2020.00979

\section{Physiological Predictors of Maximal Incremental Running Performance}

\author{
Fábio J. Lanferdini" ${ }^{*}$, Edson S. Silva ${ }^{2}$, Esthevan Machado², Gabriela Fischer ${ }^{1}$ and \\ Leonardo A. Peyré-Tartaruga ${ }^{2}$ \\ ${ }^{1}$ Laboratório de Biomecânica, Centro de Desportos, Universidade Federal de Santa Catarina, Florianópolis, Brazil, \\ ${ }^{2}$ Laboratório de Pesquisa do Exercício, Escola de Educação Física, Fisioterapia e Dança, Universidade Federal do Rio \\ Grande do Sul, Porto Alegre, Brazil
}

Purpose: The aim of this study was to verify whether physiological components [vertical jumps (Squat Jump - SJ and Countermovement Jump - CMJ), eccentric utilization ratio (EUR) of vertical jumps, running economy (RE), metabolic cost $\left(\mathrm{C}_{M E T}\right)$, first and second ventilatory threshold $\left(\mathrm{VT}_{1}\right.$ and $\left.\mathrm{VT}_{2}\right)$ maximal oxygen uptake $\left(\mathrm{VO}_{2 \mathrm{MAX}}\right)$ ] can predict maximal endurance running performance.

Methods: Twenty male runners performed maximal vertical jumps, submaximal running at constant speeds, and maximal incremental running test. Before, we measured anthropometric parameters (body mass and height) and registered the training history and volume. SJ and CMJ tests were evaluated prior to running tests. Initially, the oxygen uptake $\left(\mathrm{VO}_{2}\right)$ was collected at rest in the orthostatic position for 6 min. Soon after, a 10-min warm-up was performed on the treadmill at $10 \mathrm{~km} \cdot \mathrm{h}^{-1}$, followed by two 5 -min treadmill rectangular tests at 12 and $16 \mathrm{~km} \cdot \mathrm{h}^{-1}$ monitored by a gas analyzer. After that, the runners performed a maximal incremental test, where the $\mathrm{VT}_{1}, \mathrm{VT}_{2}$, and $\mathrm{VO}_{2 \mathrm{MAX}}$ were evaluated, as well as the maximum running speed $\left(\mathrm{VVO}_{2 M A X}\right)$. Thus, $\mathrm{RE}$ and $\mathrm{C}_{M E T}$ were calculated with data obtained during rectangular running tests. Multivariate stepwise regression analyses were conducted to measure the relationship between independent variables (height and power of SJ and CMJ, EUR; RE and $\mathrm{C}_{M E T} 12$ and $16 \mathrm{~km} \cdot \mathrm{h}^{-1} ; \mathrm{VT}_{1}, \mathrm{VT}_{2}$, and $\mathrm{VO}_{2 \mathrm{MAX}}$ ), as predictors of maximal running performance $\left(\mathrm{VVO}_{2 M A X}\right)$, with significance level at $\alpha=0.05$.

Results: We found that $\mathrm{VO}_{2 M A X}$ and $\mathrm{RE}$ at $16 \mathrm{~km} \cdot \mathrm{h}^{-1}$ predict $81 \%$ of performance $\left(\mathrm{VVO}_{2 M A X}\right)$ of endurance runners $(0<0.001)$.

Conclusion: The main predictors of the maximal incremental running test performance were $\mathrm{VO}_{2 M A X}$ and $\mathrm{RE}$.

Keywords: runners, incremental test, $\mathrm{VO}_{2 M A X}$, running economy, metabolic cost

\section{INTRODUCTION}

Improvements of endurance running performance are based on improvements of the physiological predictors such as the maximal oxygen uptake $\left(\mathrm{VO}_{2 M A X}\right)$, running economy (RE) and metabolic thresholds (McLaughlin et al., 2010). The determinants of the endurance performance model demonstrate how the individual's $\mathrm{VO}_{2 M A X}$ determines the upper limit of aerobic metabolism 
(Bassett and Howley, 2000). Therefore, $\mathrm{VO}_{2 M A X}$ has an important relationship with endurance running performance (McLaughlin et al., 2010). However, trained runners may have similar $\mathrm{VO}_{2 M A X}$ values and thus other physiological indexes can contribute for the success of predominantly aerobic events such as RE and lactate threshold (Kipp et al., 2019).

Running speed is then determined by how efficiently the corresponding oxidative adenosine triphosphate turnover at the fractional utilization of $\mathrm{VO}_{2 M A X}$ is converted to locomotion (i.e., RE) (Joyner and Coyle, 2008). Metabolic effectiveness refers to the utilization of available energy to provide optimal performance, whereas cardiopulmonary efficiency to least work output for the processes related to oxygen transport and utilization (Daniels, 1985; Saunders et al., 2004; Peyre-Tartaruga and Coertjens, 2018). Therefore, RE is an important physiological determinant for the endurance performance (Daniels, 1985; Kipp et al., 2019). Improvements in RE allow athletes to run at a faster velocity for the same oxygen uptake $\left(\mathrm{VO}_{2}\right)$ and thus achieve superior performances (Hoogkamer et al., 2016, 2017). Accordingly, 1\% improvements in RE should directly translate to $\sim 1 \%$ faster running $3000 \mathrm{~m}$ of running (Hoogkamer et al., 2016).

Another approach used to evaluate the metabolic economy in distance running is the metabolic cost $\left(\mathrm{C}_{M E T}\right)$ for running, which is independent of the speed during indoor tests (Arellano and Kram, 2014). Therefore, the amount of metabolic energy used to run a given distance is the same (Margaria et al., 1963; Arellano and Kram, 2014; Lacour and Bourdin, 2015). In addition, according to di Prampero et al. (1986), runners with higher $\mathrm{VO}_{2 M A X}$ (direct relation) and lower $\mathrm{C}_{M E T}$ (inverse relation), could present better performance. However, no study has been found to examine the relationship between $\mathrm{C}_{M E T}$ and the velocity at $\mathrm{VO}_{2 M A X}\left(\mathrm{vVO}_{2 M A X}\right)$.

Furthermore, muscle strength or power are other important factor in predicting endurance running performance (Dumke et al., 2010), which can be assessed by performing maximal vertical jumps [squat jump (SJ) and countermovement jump $(\mathrm{CMJ})$, more similar to the motor gesture performed during the race]. Previous research showed that improved strength and power results in better RE and performance (BalsalobreFernandez et al., 2016). This may occur probably by the changes in muscle power and tendon stiffness (Kubo et al., 2007). Therefore, the performance of vertical jumps (height and power), could be related to the maximum performance of runners.

Accordingly, relating all these physiological aspects to the maximum running performance can help coaches and runners understand which features can predict performance and decide whether it is important to offer time for training specific system adaptation during regular running training. Our goal was to verify the relationship between physiological parameters $\left[\mathrm{VO}_{2 M A X}\right.$, first and second ventilatory threshold ( $\mathrm{VT}_{1}$ and $\mathrm{VT}_{2}$ ), $\mathrm{RE}, \mathrm{C}_{M E T}$ and height and power of vertical jumps (SJ and $\mathrm{CMJ}$ ) and eccentric utilization ratio (EUR) of vertical jumps] on prediction of maximal incremental running performance (maximum running speed - $\mathrm{vVO}_{2 M A X}$ ). We hypothesized that the determinants of maximal incremental running performance were $\mathrm{VO}_{2 M A X}$ and lower RE.

\section{MATERIALS AND METHODS}

\section{Participants}

Twenty male recreational runners, with $\sim 34 \pm 8$ years of age, participated in this study. Running experience was $\sim 5.5$ years, and training volume was $\sim 63 \pm 32 \mathrm{~km} /$ week. Before the selection interview, all procedures were presented to the participants, who signed a consent form to participate in the study that was approved by the local ethics committee (No. 2.437.616), according to the Declaration of Helsinki. Male runners with ages between 18 and 45 years, 2 years of running experience, training volume of at least $30 \mathrm{~km} /$ week and reaching a minimum speed of $19 \mathrm{~km} \cdot \mathrm{h}^{-1}$ in the incremental test were included in the present study. Participants were excluded if (1) they had any musculoskeletal injury of the lower and/or the upper limbs; (2) they had any contra-indications for maximal effort (cardiovascular, musculoskeletal, respiratory, or neurologic diseases); and (3) they had any difficulty in understanding and/or executing of the tests.

\section{Experimental Design}

Runners attended to one testing day in the laboratory. Anthropometric, maximal vertical jumps (SJ and CMJ), constant running speed, and maximal incremental running test $\left[\mathrm{VO}_{2}\right.$ was measured] were performed (Figure 1).

\section{Procedures}

\section{Anthropometry}

Anthropometry was evaluated according to the International Society for Advancement of Kineanthropometry (Marfell-Jones et al., 2012).

\section{Vertical Jumps (SJ and CMJ)}

The runners performed the SJ and CMJ using a jumping mat (Jump System Pro ${ }^{\circledR}$, CEFISE, Nova Odessa, Brazil), with sample rate of $1000 \mathrm{~Hz}$. Each athlete performed three attempts of the SJ and CMJ with maximal effort. Thirty seconds between attempts were given to each runner. Both vertical jumps were performed according to the recommendations of Bosco et al. (1983). The runners were instructed to jump as high as possible, with their hands on their hips. The variables used in the data analysis were jump height $(\mathrm{cm})$, power output $(\mathrm{PO})$ and $\mathrm{PO}$ normalized by the body mass $\left(\mathrm{W} \cdot \mathrm{kg}^{-1}\right)$. In addition, the eccentric utilization ratio (EUR) was calculated: EUR jump height [EURHJ (CMJ-SJ); ( $\triangle \mathrm{CMJ}-\mathrm{SJ})$; and $(\mathrm{CMJ} / \mathrm{SJ})]$ and EUR of peak power output [EUR-PO (CMJ-SJ); ( $\Delta \mathrm{CMJ}-\mathrm{SJ})$; (CMJ/SJ)]. Prestretch augmentation can be calculated as a percentage with percentage pre-stretch increase [EUR $(\Delta \mathrm{CMJ}-\mathrm{SJ})]$. Additional approach is to amount reactive strength [EUR (CMJ-SJ)], as described in McGuigan et al. (2006).

\section{Running Economy and Metabolic Cost}

All the participants underwent familiarization on a treadmill (Super ATL, Inbrasport-Inbramed, Porto Alegre, Brazil). The $\mathrm{VO}_{2}$ was measured breath by breath during the incremental test using an open-circuit indirect calorimetry system (Cosmed, Quark CPET, Rome, Italy). Initially, the $\mathrm{VO}_{2}$ was collected at 


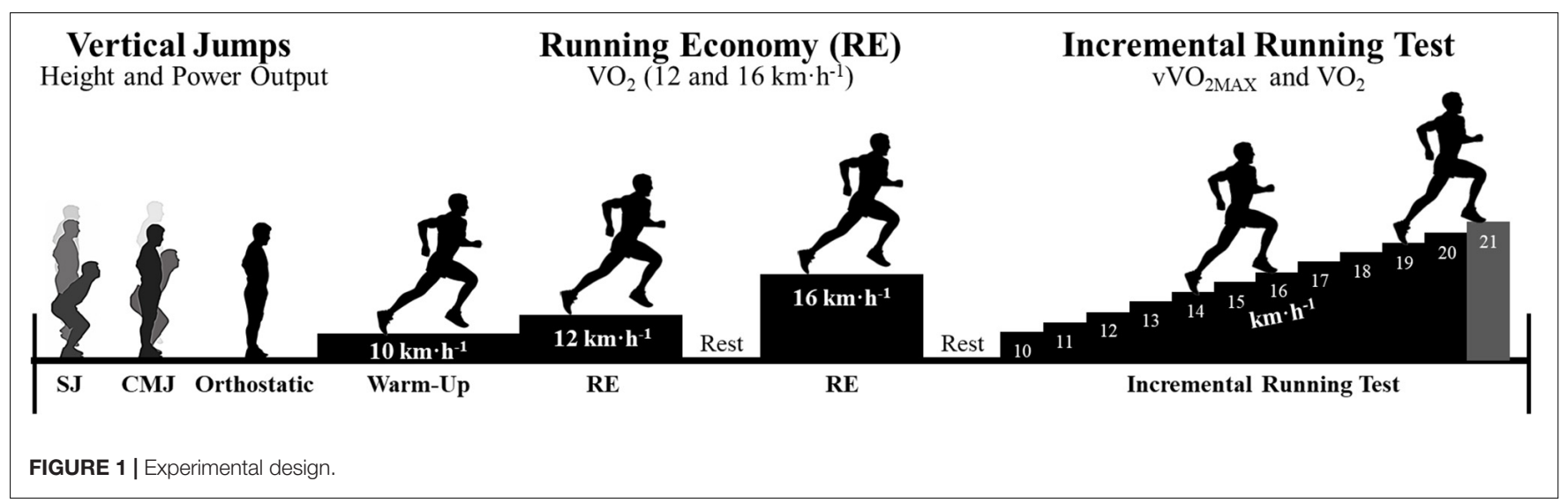

rest in the orthostatic position for $6 \mathrm{~min}$. Soon after, a 10 min warm-up was performed on the treadmill at $10 \mathrm{~km} \cdot \mathrm{h}^{-1}$, after which the constant speed running test was performed for $5 \mathrm{~min}$ at 12 and $16 \mathrm{~km} \cdot \mathrm{h}^{-1}$, with a 5 -min interval between each test (Saunders et al., 2004). The treadmill velocity was calibrated before tests (Mocap System), by digitizing an adhesive retro-reflective marker on the tread belt as it traveled along the length of the treadmill. In addition, parameters including room temperature and humidity were measured using the same gas analyzer (Cosmed, Quark CPET, Rome, Italy). The $\mathrm{VO}_{2}$ curves from $\mathrm{RE}$ tests were analyzed using the software PFT ergo (Cosmed, Quark CPET, Rome, Italy), and the mean $\mathrm{VO}_{2}$ values were calculated and plotted at the last minute of each bout. $\mathrm{RE}$ was defined as the relationship between $\mathrm{VO}_{2}$ and the running velocity (Daniels, 1985). The metabolic power $\left(\mathrm{W}_{M E T}\right)$ was considered the difference between the $\mathrm{VO}_{2}$ measured during exercise and the $\mathrm{VO}_{2}$ at rest. Because the unit of measure used was Watts (W), this difference was multiplied by the energy coefficient (20.9 $\left.\mathrm{J} \cdot \mathrm{mL}^{-1}\right)$ and divided by the time in seconds $(60 \mathrm{~s})$. The $\mathrm{C}_{M E T}$ values relative to the speeds of 12 and $16 \mathrm{~km} \cdot \mathrm{h}^{-1}$ were calculated by dividing $\mathrm{W}_{M E T}$ by the speed in $\mathrm{m} \cdot \mathrm{s}^{-1}$ (di Prampero et al., 1986).

\section{Maximum Incremental Test}

The runners were submitted to a maximal incremental test (Figure 1). It started with an initial velocity of $10 \mathrm{~km} \cdot \mathrm{h}^{-1}$, and $1 \mathrm{~km} \cdot \mathrm{h}^{-1}$ was added per minute until exhaustion (Bentley et al., 2007). The $\mathrm{VO}_{2}$ obtained during the maximal incremental test was evaluated on the treadmill and followed a similar gas analysis as described above.

The $\mathrm{VO}_{2}$ analysis during the maximal incremental test was performed by visual inspection. $\mathrm{VO}_{2}$ values were plotted to exclude values with four standard deviations above or below the average of the movable windows of the whole curve-average of three breaths in each window (Fernandes et al., 2012). During the maximum incremental test, the $\mathrm{vVO}_{2 M A X}$ was obtained from the last completed stage, while the $\mathrm{VO}_{2 M A X}$ was determined as the highest value observed in the last test stage (Bentley et al., 2007). Also, gas exchange data were analyzed to define the $\mathrm{VT}_{1}$ and $\mathrm{VT}_{2}$, as described in Bentley et al. (2007).

\section{Statistical Analysis}

Data normality and homogeneity were assessed by the ShapiroWilk and Mauchly tests, respectively. Stepwise multiple linear regression method was used to estimate the relative contributions of independent variables [SJ (cm); PO-SJ (W); PO-SJr $\left(\mathrm{W} \cdot \mathrm{kg}^{-1}\right)$; CMJ (cm); PO-CMJ (W); PO-CMJr (W. $\left.\mathrm{kg}^{-1}\right)$; EUR-HJ (CMJ-SJ); EUR-HJ ( $\triangle \mathrm{CMJ}-\mathrm{SJ}) ; \mathrm{EUR}-\mathrm{HJ}$ (CMJ/SJ); EUR-PO (CMJ-SJ); EUR-PO ( $\triangle \mathrm{CMJ}-\mathrm{SJ}) ; \mathrm{EUR}-\mathrm{PO}(\mathrm{CMJ} / \mathrm{SJ}) ; \mathrm{VO}_{2 M A X}$ $\left(\mathrm{ml} \cdot \mathrm{kg}^{-1} \cdot \mathrm{min}^{-1}\right) ; \mathrm{VT}_{2}$ and $\mathrm{VT}_{1}\left(\mathrm{ml} \cdot \mathrm{kg}^{-1} \cdot \mathrm{min}^{-1}\right) ; \mathrm{RE} 12$ and $16 \mathrm{~km} \cdot \mathrm{h}^{-1}\left(\mathrm{ml} \cdot \mathrm{kg}^{-1} \cdot \mathrm{min}^{-1}\right) ; \mathrm{C}_{M E T} 12$ and $16 \mathrm{~km} \cdot \mathrm{h}^{-1}$ $\left.\left(\mathrm{J} \cdot \mathrm{kg}^{-1} \cdot \mathrm{m}^{-1}\right)\right]$ on the dependent variable of the performance $\left[\mathrm{vVO}_{2 M A X}\left(\mathrm{~km} \cdot \mathrm{h}^{-1}\right)\right]$. Our collinearity diagnostic exploration resulted in variance inflation factors of $<2.0$ and tolerance of $0.10-0.70$, which indicate acceptable levels of multicollinearity of the variables (Dormann et al., 2012). Statistical analysis was performed with SPSS 20.0 for Windows, with a significance level of $\alpha=0.05$.

\section{RESULTS}

Anthropometric, physiological, training characteristics and performance of runners are summarized in Table 1.

Table 2 shows the contribution of positive $\mathrm{VO}_{2 M A X}$ and negative $\mathrm{RE} 16 \mathrm{~km} \cdot \mathrm{h}^{-1}$ (81\%) during incremental running test.

Figure 2 shows the contribution of positive $\mathrm{VO}_{2 M A X}$ and negative $\mathrm{RE} 16 \mathrm{~km} \cdot \mathrm{h}^{-1}$ (81\%) during incremental running test.

\section{DISCUSSION}

The purpose of this study was to investigate the role of physiological parameters on predicting $\mathrm{VVO}_{2 M A X}$ in recreational runners. The primary finding of this study is that the main determinants of running performance are $\mathrm{VO}_{2 M A X}$ and $\mathrm{RE}$ at $16 \mathrm{~km} \cdot \mathrm{h}^{-1}$. It is worth noting that the RE evaluated at speed close to $\mathrm{vVO}_{2 \text { MAX }}\left(16 \mathrm{~km} \cdot \mathrm{h}^{-1}\right)$ was better related than $\mathrm{RE}$ at low speed $\left(12 \mathrm{~km} \cdot \mathrm{h}^{-1}\right)$. Importantly, this study examined, for the first time, the determinants of $\mathrm{vVO}_{2 M A X}$ in recreational runners, demonstrating that physiological but not neuromuscular factors were associated with performance in this condition. 
TABLE 1 | Descriptive values of all variables evaluated of runners.

\begin{tabular}{|c|c|c|c|c|}
\hline & Mean & SD & CV (\%) & Range \\
\hline Age (years) & 34.0 & 7.9 & 23.4 & $22-48$ \\
\hline Body mass (kg) & 67.2 & 6.1 & 9.1 & $55.6-80.2$ \\
\hline Height (cm) & 173.6 & 7.0 & 4.1 & $160-186$ \\
\hline Experience (years) & 5.5 & 2.5 & 45.1 & $3-14$ \\
\hline Training frequency (days/week) & 7.6 & 6.8 & 89.1 & $25-140$ \\
\hline Training volume (km/week) & 63.0 & 32.1 & 50.9 & $2-28$ \\
\hline $\mathrm{VO}_{2 M A X}\left(\mathrm{ml} \cdot \mathrm{kg}^{-1} \cdot \mathrm{min}^{-1}\right)$ & 63.2 & 6.4 & 10.2 & $50.5-74.5$ \\
\hline $\mathrm{HR}_{\text {MAX }}(\mathrm{bmp})$ & 184.2 & 10.6 & 5.7 & $166-201$ \\
\hline $\mathrm{VT}_{1}\left(\mathrm{ml} \cdot \mathrm{kg}^{-1} \cdot \mathrm{min}^{-1}\right)$ & 37.6 & 5.9 & 15.7 & $23.1-50.7$ \\
\hline $\mathrm{VT}_{2}\left(\mathrm{ml} \cdot \mathrm{kg}^{-1} \cdot \mathrm{min}^{-1}\right)$ & 53.5 & 6.1 & 11.3 & $35.9-62.7$ \\
\hline $\mathrm{RE} 12\left(\mathrm{ml} \cdot \mathrm{kg}^{-1} \cdot \mathrm{min}^{-1}\right)$ & 41.1 & 3.1 & 7.6 & $37.4-49.1$ \\
\hline $\operatorname{RE} 12\left(\% \mathrm{VO}_{2 M A X}\right)$ & 65.1 & 5.5 & 8.5 & $52.8-74.2$ \\
\hline $\mathrm{RE} 16\left(\mathrm{ml} \cdot \mathrm{kg}^{-1} \cdot \mathrm{min}^{-1}\right)$ & 52.7 & 3.3 & 6.3 & $46.2-61.5$ \\
\hline $\mathrm{RE} 16\left(\% \mathrm{VO}_{2 M A X}\right)$ & 83.5 & 7.1 & 8.5 & $69.4-93.1$ \\
\hline $\mathrm{C}_{\text {MET }} 12\left(\mathrm{~J} \cdot \mathrm{kg}^{-1} \cdot \mathrm{m}^{-1}\right)$ & 3.7 & 0.3 & 8.7 & $3.3-4.6$ \\
\hline $\mathrm{C}_{M E T} 16\left(\mathrm{~J} \cdot \mathrm{kg}^{-1} \cdot \mathrm{m}^{-1}\right)$ & 3.7 & 0.2 & 6.9 & $3.3-4.4$ \\
\hline SJ (cm) & 30.3 & 4.7 & 15.6 & $22.6-39.1$ \\
\hline PO-SJ (W) & 1604 & 202 & 12.6 & 1272-1955 \\
\hline PO-SJr $\left(\mathrm{W} \cdot \mathrm{kg}^{-1}\right)$ & 23.9 & 1.9 & 7.9 & $20.6-27.2$ \\
\hline $\mathrm{CMJ}(\mathrm{cm})$ & 31.6 & 4.6 & 14.4 & $25.2-39.8$ \\
\hline $\mathrm{PO}-\mathrm{CMJ}(\mathrm{W})$ & 1634 & 210 & 12.9 & 1298-1964 \\
\hline PO-CMJr $\left(\mathrm{W} \cdot \mathrm{kg}^{-1}\right)$ & 24.4 & 1.8 & 7.2 & $21.8-27.4$ \\
\hline EUR-HJ (CMJ-SJ) & 1.7 & 1.4 & 83.3 & -0.8 to 4.4 \\
\hline EUR-PO (CMJ-SJ) & 45.9 & 39.1 & 85.1 & -17.9 to 113.6 \\
\hline EUR-HJ ( $\Delta$ CMJ-SJ) & 5.8 & 4.6 & 79.9 & -2.2 to 13.1 \\
\hline EUR-PO ( $\Delta$ CMJ-SJ) & 2.8 & 2.3 & 80.1 & -1.1 to 6.4 \\
\hline EUR-HJ (CMJ/SJ) & 1.1 & 0.1 & 4.4 & $1.0-1.1$ \\
\hline EUR-PO (CMJ/SJ) & 1.0 & 0.0 & 2.2 & $1.0-1.1$ \\
\hline $\mathrm{VVO}_{2 M A X}\left(\mathrm{~km} \cdot \mathrm{h}^{-1}\right)$ & 20.6 & 1.5 & 7.4 & $19-25$ \\
\hline
\end{tabular}

$\mathrm{VO}_{2 M A X}$, maximal oxygen uptake; $H R_{M A X}$, maximal heart; $V T_{2}$, second ventilatory threshold; $V T_{1}$, first ventilatory threshold; $R E$, running economy; $C_{M E T}$, metabolic cost; SJ, squat jump; PO-SJ, power output of squat jump; PO-SJr, relative power output of squat jump; CMJ: countermovement jump; PO-CMJ: power output of countermovement jump; PO-CMJr, relative power output of countermovement jump; EUR-HJ, eccentric utilization ratio-jump height; EUR-PO, eccentric utilization ratio-power output; $V V_{2 M A X}$, maximum running speed.

Indeed, the $\mathrm{VO}_{2 M A X}$ and $\mathrm{RE}$ at $16 \mathrm{~km} \cdot \mathrm{h}^{-1}$ (Table 2 and Figure 2) accounted for $81 \%$ of the variance in performance of incremental running test $\left(\mathrm{vVO}_{2 M A X}\right)$. Conversely, the $\mathrm{C}_{M E T}$, $\mathrm{VT}_{1}, \mathrm{VT}_{2}, \mathrm{SJ}$ and $\mathrm{CMJ}$ (height and power output) and EUR (height and power output) did not enter in the regression model to predict $\mathrm{vVO}_{2 M A X}$. These results complement what have already been found in the literature as predictors of maximal endurance running performance. These results agree with previous studies, which indicate $\mathrm{VO}_{2 M A X}$ and $\mathrm{RE}$, as two of the main predictors of running endurance performance (Conley and Krahenbuhl, 1980; Bassett and Howley, 2000; McLaughlin et al., 2010; Kipp et al., 2019). In general, the relationship between $\mathrm{VO}_{2 M A X}$ and running performance was similar to other studies using well-trained runners, confirming its importance as a physiological variable linked to distance running performance (Costill et al., 1973; Noakes et al., 1990; McLaughlin et al., 2010). According to McLaughlin et al. (2010), $\mathrm{VO}_{2 M A X}$ explained 81\% of the total variance, and RE accounted for an additional $11 \%$ of the $16-\mathrm{km}$ endurance running performance.

The running performance is related to better RE (e.g., a lower $\mathrm{VO}_{2}$ for a given running speed) may be worthwhile, especially in endurance events, once it will allow a lower fractional $\mathrm{VO}_{2 M A X}$ utilization for any submaximal intensity exercise (Daniels, 1985; Barnes and Kilding, 2015). Therefore, runners with the same $\mathrm{VO}_{2 M A X}$ can present different performances, and this can be explained in part by the RE, as demonstrated here. Results of the current study are in line with previous findings (Noakes et al., 1990; Tartaruga et al., 2012, 2014). For example, Noakes et al. (1990) found a strong correlation between performance and RE ( $r=0.76-0.90)$, without regression test to identify the determination percentage between $\mathrm{RE}$ and running performance. Therefore, several physiological and biomechanical factors seem to influence RE in highly trained runners and must be taken into account to enable improvements in RE. These factors include metabolic adaptations within the muscle such as increased mitochondria and oxidative enzymes (Saunders et al., 2004), the ability of the muscles to store and release elastic energy by increasing the stiffness and other key parameters of elastic mechanism (da Rosa et al., 2019), more efficient mechanics leading to less energy wasted on braking forces and high vertical oscillation and stride frequency and stride length (Saunders et al., 2004; Tartaruga et al., 2009, 2012).

However, the multiple linear regression test showed no relationship between the $\mathrm{C}_{M E T}$ and the performance in a maximal incremental test. In addition to the expected collinearity between $\mathrm{RE}$ and $\mathrm{C}_{M E T}$, the higher regression coefficient between $\mathrm{RE}$ and performance than between $\mathrm{C}_{M E T}$ and performance is probably due to the role of basal metabolism contributing to this relationship (Saibene and Minetti, 2003). Moreover, training with vertical jumps promotes strength and power and consequently can improve RE and performance (Kubo et al., 2007; Balsalobre-Fernandez et al., 2016). The results of the present study demonstrate that there is no relationship between the neuromuscular outcomes from vertical jumps (SJ and $\mathrm{CMJ}$ ) and the maximum endurance running performance in recreational runners that did not performed previously strength and power training programs. Conversely, according to Loturco et al. (2015), the performance of vertical jumps (SJ

TABLE 2 | Predictors of performance during maximal incremental running test $\left(\mathrm{VVO}_{2 M A X}\right)$.

\begin{tabular}{|c|c|c|c|c|c|}
\hline Dependent variable & $r^{2}$ & $\boldsymbol{P}$ & Indicator & Standardized coefficients $(\beta)$ & $p$ \\
\hline \multirow[t]{2}{*}{$\mathrm{VVO}_{2 M A X}\left(\mathrm{~km} \cdot \mathrm{h}^{-1}\right)$} & 0.81 & $<0.001$ & $\mathrm{VO}_{2 M A X}$ & 0.95 & $<0.001$ \\
\hline & & & $\mathrm{RE} 16 \mathrm{~km} \cdot \mathrm{h}^{-1}$ & -0.85 & $<0.001$ \\
\hline
\end{tabular}

$\mathrm{VO}_{2 M A x}$, maximal oxygen uptake; $R E$, running economy. 


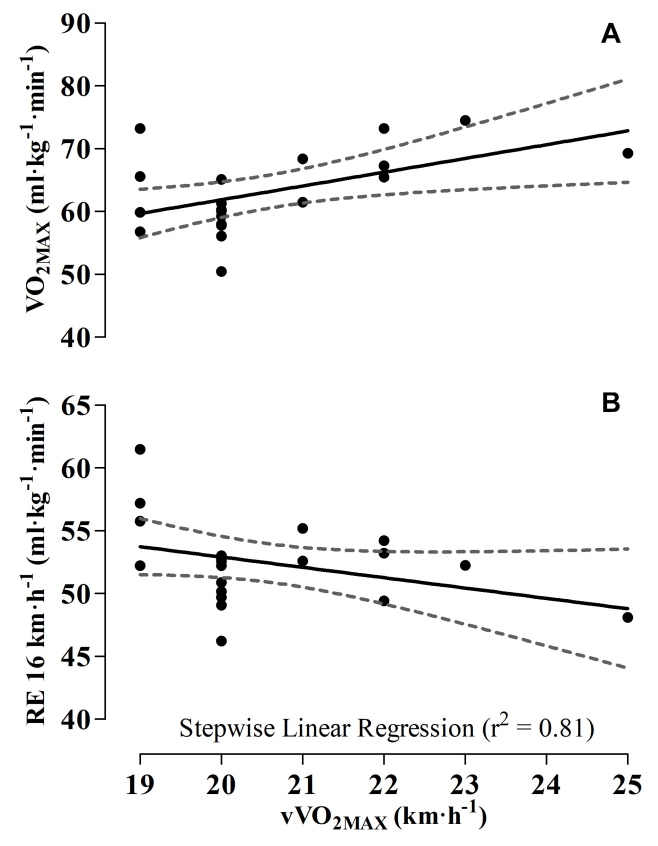

FIGURE 2 | Predicted improvement maximal incremental of running performance $\left(\mathrm{VVO}_{2 M A X}\right)$ with $\mathrm{VO}_{2 \text { MAX }}(\mathbf{A})$ and $\mathrm{RE}(\mathbf{B})$.

and CMJ) had a strong correlation $(r>0.8)$ with the sprinting running performance $(100 \mathrm{~m})$. Thus, the use of variables from vertical jumps seems to be more suitable for predicting performance in sprints tests, but not for endurance tests. Collectively, the present findings confirm the role of maximal oxygen utilization and metabolic economy on the $\mathrm{vVO}_{2 M A X}$ (Billat et al., 2000).

\section{LIMITATIONS}

The main physiological limitation of the present study was that blood lactate was not evaluated during the maximal incremental running performance, that would allow to identify if the lactate threshold also and would determine endurance performance of the runners (Kipp et al., 2019). Another limitation of the present study was the fact that all evaluations were performed in a single day and, therefore, the last test performed (maximal incremental test) may have suffered interference from the a priori tests causing the establishment of processes of muscular fatigue. However, the athletes evaluated were well trained and an interval of $5 \mathrm{~min}$ was adopted between each condition, minimizing the effects of muscle fatigue. It is important to highlight that future studies should control for the following variables that were controlled in our study: runners' age, experience, training volume and competitive level. The control of these variables reinforces the novel approach we used in this study.

\section{FUTURE PERSPECTIVES}

Our analysis here focused solely on the oxygen uptake during maximal incremental running and vertical jumps
(SJ and CMJ) performance. Therefore, future studies can evaluate the prediction of endurance running performance through the use of other physiological (e.g., skeletal muscle respiration), neuromuscular (e.g., muscle activation and size) and biomechanical (e.g., mechanics work and efficient) variables. Besides that, the decisive step will be an actual sport-setting test, such as during a running race (e.g., $3000 \mathrm{~m}$ ), to identify which physiological, neuromuscular and biomechanical variables determine endurance running performance.

\section{PRACTICAL APPLICATION}

Understanding which variables can be predictors of running performance in a laboratory setting may contribute to athletes, coaches and sport scientists when determining physiological behaviors that may lead to the best performance, despite these predictors may not be the same for the outdoor or sports competition conditions, where other variables physiological and biomechanics may play an important role. These findings suggest that interventions that enhance $\mathrm{VO}_{2 M A X}$ and $\mathrm{RE}$ may increase the runners' $\mathrm{vVO}_{2}$ and improve their running performance.

\section{CONCLUSION}

In summary, according to the outcomes presented in this study, it can be concluded that maximal aerobic performance prediction depends $81 \%$ on $\mathrm{VO}_{2 M A X}$ and $\mathrm{RE}$ at $16 \mathrm{~km} \cdot \mathrm{h}^{-1}$. However, we suggested that further studies should be carried out with these and other physiological and biomechanical variables to determine performance in ecological conditions (e.g., athletics track tests) or during endurance running competitions.

\section{DATA AVAILABILITY STATEMENT}

The raw data supporting the conclusions of this article are available in Supplementary Material.

\section{ETHICS STATEMENT}

The studies involving human participants were reviewed and approved by Universidade Federal do Rio Grande do Sul (No. 2.437.616). The patients/participants provided their written informed consent to participate in this study.

\section{AUTHOR CONTRIBUTIONS}

FL was responsible for the conception, acquisition of data, analysis and interpretation of data, drafting of the manuscript and revising it critically for important intellectual content, and final approval of the version to 
be submitted, and was the corresponding author. EM and GF were responsible for the acquisition of data and analysis, drafting of the manuscript and revising it critically for important intellectual content, and final approval of the version to be submitted. EM was responsible for the data analysis, critical revision of the manuscript, and final approval of the version to be submitted. LP-T was responsible for the data analysis and design of the study, study orientation, supervision, critical revision of the manuscript, and final approval of the version to be submitted. All authors contributed to the article and approved the submitted version.

\section{REFERENCES}

Arellano, C. J., and Kram, R. (2014). Partitioning the metabolic cost of human running: a task-by-task approach. Integr. Comp. Biol. 54, 1084-1098. doi: 10.1093/icb/icu033

Balsalobre-Fernandez, C., Santos-Concejero, J., and Grivas, G. V. (2016). Effects of strength training on running economy in highly trained runners: a systematic review with meta-analysis of controlled trials. J. Strength Cond. Res. 30, 2361-2368. doi: 10.1519/jsc.000000000 0001316

Barnes, K. R., and Kilding, A. E. (2015). Running economy: measurement, norms, and determining factors. Sports Med. Open 1:8.

Bassett, D. R. Jr., and Howley, E. T. (2000). Limiting factors for maximum oxygen uptake and determinants of endurance performance. Med. Sci. Sports Exerc. 32, 70-84.

Bentley, D. J., Newell, J., and Bishop, D. (2007). Incremental exercise test design and analysis: implications for performance diagnostics in endurance athletes. Sports Med. 37, 575-586. doi: 10.2165/00007256-20073707000002

Billat, V. L., Slawinski, J., Bocquet, V., Demarle, A., Lafitte, L., Chassaing, P., et al. (2000). Intermittent runs at the velocity associated with maximal oxygen uptake enables subjects to remain at maximal oxygen uptake for a longer time than intense but submaximal runs. Eur. J. Appl. Physiol. 81, 188-196. doi: $10.1007 / \mathrm{s} 004210050029$

Bosco, C., Mognoni, P., and Luhtanen, P. (1983). Relationship between isokinetic performance and ballistic movement. Eur. J. Appl. Physiol. Occup. Physiol. 51, 357-364. doi: 10.1007/bf00429072

Conley, D. L., and Krahenbuhl, G. S. (1980). Running economy and distance running performance of highly trained athletes. Med. Sci. Sports Exerc. 12, 357-360. doi: 10.1249/00005768-198012050-00010

Costill, D. L., Thomason, H., and Roberts, E. (1973). Fractional utilization of the aerobic capacity during distance running. Med. Sci. Sports 5, 248-252.

da Rosa, R. G., Oliveira, H. B., Gomenuka, N. A., Masiero, M. P. B., Da Silva, E. S., Zanardi, A. P. J., et al. (2019). Landing-takeoff asymmetries applied to running mechanics: a new perspective for performance. Front. Physiol. 10:415. doi: 10.3389/fphys.2019.00415

Daniels, J. T. (1985). A physiologist's view of running economy. Med. Sci. Sports Exerc. 17, 332-338.

di Prampero, P. E., Atchou, G., Bruckner, J. C., and Moia, C. (1986). The energetics of endurance running. Eur. J. Appl. Physiol. Occup. Physiol. 55, 259-266. doi: 10.1007/bf02343797

Dormann, C. F., Elith, J., Bacher, S., Buchmann, C., Carl, G., Carré, G., et al. (2012). Collinearity: a review of methods to deal with it and a simulation study evaluating their performance. Ecography 36, 27-46. doi: 10.1111/j.1600-0587. 2012.07348.x

Dumke, C. L., Pfaffenroth, C. M., Mcbride, J. M., and Mccauley, G. O. (2010). Relationship between muscle strength, power and stiffness and running economy in trained male runners. Int. J. Sports Physiol. Perform. 5, 249-261. doi: 10.1123/ijspp.5.2.249

Fernandes, R. J., De Jesus, K., Baldari, C., Sousa, A. C., Vilas-Boas, J. P., and Guidetti, L. (2012). Different VO2max time-averaging intervals in

\section{ACKNOWLEDGMENTS}

The authors wish to specially thank the athletes for their participation and cooperation in this study.

\section{SUPPLEMENTARY MATERIAL}

The Supplementary Material for this article can be found online at: https://www.frontiersin.org/articles/10.3389/fphys. 2020.00979/full\#supplementary-material

swimming. Int. J. Sports Med. 33, 1010-1015. doi: 10.1055/s-00321316362

Hoogkamer, W., Kipp, S., Spiering, B. A., and Kram, R. (2016). Altered running economy directly translates to altered distance-running performance. Med. Sci. Sports Exerc. 48, 2175-2180. doi: 10.1249/mss.00000000000 01012

Hoogkamer, W., Kram, R., and Arellano, C. J. (2017). How Biomechanical Improvements in Running Economy Could Break the 2-hour Marathon Barrier. Sports Med. 47, 1739-1750. doi: 10.1007/s40279-0170708-0

Joyner, M. J., and Coyle, E. F. (2008). Endurance exercise performance: the physiology of champions. J. Physiol. 586, 35-44. doi: 10.1113/jphysiol.2007. 143834

Kipp, S., Kram, R., and Hoogkamer, W. (2019). Extrapolating metabolic savings in running: implications for performance predictions. Front. Physiol. 10:79. doi: 10.3389/fphys.2019.00079

Kubo, K., Morimoto, M., Komuro, T., Yata, H., Tsunoda, N., Kanehisa, H., et al. (2007). Effects of plyometric and weight training on muscletendon complex and jump performance. Med. Sci. Sports Exerc. 39, 1801-1810.

Lacour, J. R., and Bourdin, M. (2015). Factors affecting the energy cost of level running at submaximal speed. Eur. J. Appl. Physiol. 115, 651-673. doi: 10.1007/ s00421-015-3115-y

Loturco, I., Pereira, L. A., Cal Abad, C. C., D’angelo, R. A., Fernandes, V., Kitamura, K., et al. (2015). Vertical and Horizontal Jump Tests Are Strongly Associated With Competitive Performance in 100-m Dash Events. J. Strength Cond. Res. 29, 1966-1971.

Marfell-Jones, M. J., Stewart, A. D., and De Ridder, J. H. (2012). International Standards for Anthropometric Assessment. Wellington: ISAK.

Margaria, R., Cerretelli, P., Aghemo, P., and Sassi, G. (1963). Energy cost of running. J. Appl. Physiol. 18, 367-370.

McGuigan, M. R., Doyle, T. L., Newton, M., Edwards, D. J., Nimphius, S., and Newton, R. U. (2006). Eccentric utilization ratio: effect of sport and phase of training. J. Strength Cond. Res. 20, 992-995.

McLaughlin, J. E., Howley, E. T., Bassett, D. R. Jr., Thompson, D. L., and Fitzhugh, E. C. (2010). Test of the classic model for predicting endurance running performance. Med. Sci. Sports Exerc. 42, 991-997. doi: 10.1249/mss. 0b013e3181c0669d

Noakes, T. D., Myburgh, K. H., and Schall, R. (1990). Peak treadmill running velocity during the VO2 max test predicts running performance. J. Sports Sci. 8, 35-45. doi: 10.1080/02640419008732129

Peyre-Tartaruga, L. A., and Coertjens, M. (2018). Locomotion as a powerful model to study integrative physiology: efficiency. Economy, and power relationship. Front. Physiol. 9:1789. doi: 10.3389/fphys.2018.01789

Saibene, F., and Minetti, A. E. (2003). Biomechanical and physiological aspects of legged locomotion in humans. Eur. J. Appl. Physiol. 88, 297-316. doi: 10.1007/ s00421-002-0654-9

Saunders, P. U., Pyne, D. B., Telford, R. D., and Hawley, J. A. (2004). Factors affecting running economy in trained distance runners. Sports Med. 34, 465485. doi: 10.2165/00007256-200434070-00005

Tartaruga, M. P., Brisswalter, J., Peyre-Tartaruga, L. A., Avila, A. O., Alberton, C. L., Coertjens, M., et al. (2012). The relationship between running economy 
and biomechanical variables in distance runners. Res. Q. Exerc. Sport 83, 367-375.

Tartaruga, M. P., Mota, C. B., Peyre-Tartaruga, L. A., and Brisswalter, J. (2014). Scale model on performance prediction in recreational and elite endurance runners. Int. J. Sports Physiol. Perform. 9, 650-655. doi: 10.1123/ijspp.20130165

Tartaruga, M. P., Peyré-Tartaruga, L. A., Coertjens, M., De Medeiros, M. H., and Kruel, L. F. M. (2009). The influence of the allometric scale on the relationship between running economy and biomechanical variables in distance runners. Biol. Sport 26, 263-273. doi: 10.5604/20831862. 894791
Conflict of Interest: The authors declare that the research was conducted in the absence of any commercial or financial relationships that could be construed as a potential conflict of interest.

Copyright ( 2020 Lanferdini, Silva, Machado, Fischer and Peyré-Tartaruga. This is an open-access article distributed under the terms of the Creative Commons Attribution License (CC BY). The use, distribution or reproduction in other forums is permitted, provided the original author(s) and the copyright owner(s) are credited and that the original publication in this journal is cited, in accordance with accepted academic practice. No use, distribution or reproduction is permitted which does not comply with these terms. 